\title{
More risk factors, less ischemia, and the relevance of MPI testing
}

\author{
Randall C. Thompson, MD, FASNC, ${ }^{a}$ and Adel H. Allam, MD, FASNC ${ }^{b}$ \\ a St. Luke's Mid America Heart Institute, Kansas City \\ ${ }^{b}$ Al Azhar University, Alfa Scan, Cairo, Egypt
}

Received Jan 9, 2015; accepted Jan 9, 2015

doi: 10.1007/s12350-015-0072-0

\section{See related article, pp. 539-551}

Cardiologists who have practiced during the past two to three decades have undoubtedly noticed that our coronary artery disease patients fare much better than they used to. The rate of progression of disease seems to be slower, the frequency and level of severity of ischemia post-coronary intervention is less, fewer patients have difficult to control angina, and heart attack survival rates are much better. ${ }^{1}$ Cardiologists should rightfully be proud of the great progress we have made in reducing death and disability from coronary heart disease. In this issue of The Journal, Duvall and colleagues demonstrate that the frequency of abnormal myocardial perfusion imaging (MPI) studies and the frequency of ischemia seen on MPI testing have declined substantially since $1996 .^{2}$ Their study is noteworthy because it is multicenter and includes over 100,000 scans. The rich data set presented is an important snapshot of the practice of nuclear cardiology and of the progress and the practice of cardiovascular medicine over this time period.

In this report by Duvall et al, not only has the frequency of abnormal MPI studies declined since 1996, but also the number of studies performed per year has fallen in the past several years. The frequency of angiographic one vessel and multivessel coronary artery disease has shown similar decreases in the author's institutions cardiac catheterization laboratories as well. ${ }^{2}$ Although there are several potential explanations for these finding, (i.e., changing referral patterns and improved camera technology) the data taken together

Reprint requests: Randall C. Thompson, MD FASNC, St. Lukeós Mid America Heart Institute, Kansas City; rthompson@saint-lukes.org J Nucl Cardiol 2015;22:552-4.

1071-3581/\$34.00

Copyright (C) 2015 American Society of Nuclear Cardiology. particularly support the conclusion that the burden of coronary atherosclerotic disease is less than it used to be.

Data from our laboratories corroborate that the key findings in the Duvall study are a generalized phenomenon, and are not peculiar to those individual medical centers. A review of over 140,000 MPI studies performed at St. Luke's Mid America Heart institute in Kansas City between 2002 and 2014 shows a temporal trend in the frequency of ischemic studies which is very similar to that described by Duvall et al (Figure 1). Data from over 10,000 MPI studies performed at a large, premier nuclear laboratory in Cairo, Egypt (Alfa Scan) likewise show a somewhat similar temporal trend (Figure 1). The Mid America Heart Institute laboratory routinely utilizes a number of newer technologies including attenuation correction, wide beam reconstruction post-processing, positron emission tomography MPI, and high sensitivity SPECT instrumentation. Alfa Scan routinely utilizes contemporary SPECT Anger cameras with prone imaging and about $2 / 3$ of patients undergo exercise stress.

Several observations of these data are worth mentioning. First, in the Duvall study, the frequency of ischemic MPI studies leveled off about 10 years ago and has been relatively constant since then. Likewise, from the Kansas City and Cairo results shown in Figure 1, the frequency of ischemic MPI studies leveled off about 5 years ago. In fact, there is a slight increase in frequency of ischemia in years 2013 and 2014 compared to recent prior years in the Kansas City experience. This recent trend might be from the effect of Appropriate Use Criteria. For example, if more patients with low pretest likelihood of ischemia are directed to treadmill exercise testing, stress echo, or coronary CTA instead of MPI testing, the percentage of a laboratory's ischemic MPI tests can go up.

The second observation worth noting is that in the Duval study, the levels of the ischemia and of abnormal stress tests are certainly high enough to conclude, as the authors do, that MPI testing remains quite relevant. Their study is different in this regard from a large report by 


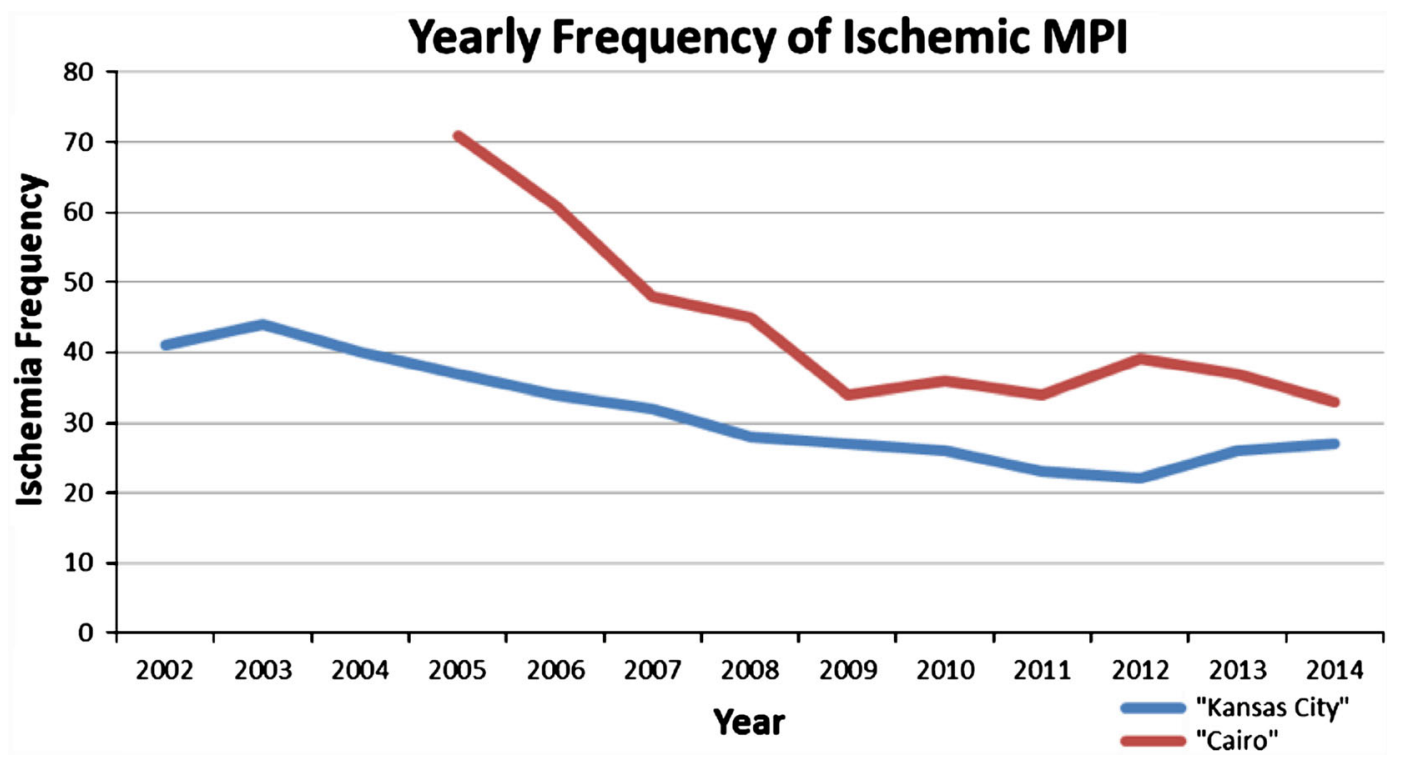

Figure 1. Yearly proportion of myocardial perfusion imaging (MPI) studies demonstrating ischemia from St. Luke's Mid America Heart Institute in Kansas City (blue line) and Alfa Scan Laboratories in Cairo, Egypt (red line).

Rozanski and colleagues which found much lower rates of ischemia and of abnormal stress test. ${ }^{3}$ The frequency of ischemic studies is somewhat higher in the Kansas City (middle of the United States) experience than in Duvall's "east coast experience" and substantially higher than in Rozanski et al's "west coast experience". The frequency of ischemic studies from Alfa Scan, Cairo is higher than in any of the reports from the US centers, perhaps reflecting the relatively lower resources of the Egyptian health care system and later presentation of coronary disease patients compared to the US. At these levels of ischemia, MPI testing clearly remains a highly relevant tool. It might also be pointed out that the overall improvement in CAD patient outcomes is probably partly related to the proper diagnosis and subsequent management of these patients afforded by such testing.

The study by Duvall et al also demonstrates that the population of patients being studied with MPI is now more obese than it was several years ago. Over time, the percentage of patients with hypertension, dyslipidemia, diabetes and a history of smoking increased as well. A greater frequency of pharmacologic stress testing was also noted compared to previous years. Despite these changes in the mix of patients referred for testing, the frequency of ischemia is now less than it was 10 years ago and has not increased very much even the past 2 years.

The reason for the improvements in the way coronary patients fare is multifactorial. For example, statin drugs greatly reduce the progression of coronary disease and their use has increased markedly during the past two decades. ${ }^{4}$ Also, drug eluting stents became commonplace in the United States in about 2003, greatly reducing the rate of restenosis post-coronary intervention. ${ }^{5}$ The population of coronary disease patients has grown over the past two decades and a greater percentage of patients now studied by nuclear stress testing are those with known coronary artery disease than in the past. ${ }^{2}$ The Duval study also confirms that there has been a particularly big drop in the number of patients with severe ischemia. This likely reflects larger trends in how our patients are managed, their outcomes, and public knowledge about heart disease. It may also reflect improvements in access to care.

The Duvall study indeed shows that MPI is still a clinically relevant medical test in a very large number of patients. This study is consistent with other data demonstrating that abnormal MPI stress test frequency fell substantially compared to prior eras, but then leveled off about 5-10 years ago. This drop in the level of ischemia is likely largely because the amount of ischemia in the population at large has fallen. Our cumulative efforts are to be applauded.

\section{Conflict of interest}

The authors have no financial conflicts.

\section{References}

1. Go AS, Mozaffarian D, Roger VL, Benjamin EJ, Berry JD, Blaha MJ, et al. Heart disease and stroke statistics-2014 update: A report from the American Heart Association. Circulation 2014;129:e28-292. 
2. Duvall WD, Rai, M, Ahlberg, AW, O’Sullivan, D, Henzlova MJ. A multi-center assessment of the temporal trends in myocardial perfusion imaging. J Nucl Card 2015;22:X-xx.

3. Rozanski A, Gransar H, Hayes SW, Min J, Friedman JD, Thomson LE, et al. Temporal trends in the frequency of inducible myocardial ischemia during cardiac stress testing: 1991 to 2009. J Am Coll Cardiol 2013;61:1054-65.

4. Cholesterol Treatment Trialists' (CCT) Collaboration Baigent C, Blackwell L, Emberson J, Holland LE, Reith C, Bhala N, Peto R,
Barnes EH, Keech A, Simes J, Collins R. Efficacy and safety of more intense lowering of LDL cholesterol: A meta-analysis of data from 170,000 participants in 26 randomized trials. Lancet 2010;376:1670-81

5. Bangalore S, Kumar S, Fusaro M, Amoroso N, Attubato MJ, Feit F, et al. Short- and long-term outcomes with drug-eluting and baremetal coronary stents: A mixed-treatment comparison analysis of 117,762 patient-years of follow-up from randomized trials. Circulation 2012;125:2873-91. 